\title{
INOVAÇÃO DE PROCESSO, PRÁTICAS AMBIENTAIS E AÇÕES SOCIAIS: O CASO DE DUAS INDÚSTRIAS METALMECÂNICAS DO RIO GRANDE DO SUL
}

\author{
PROCESS INNOVATION, ENVIRONMENTAL PRACTICES AND SOCIAL \\ ACTIONS: THE CASE OF TWO METAL-MECHANIC INDUSTRIES IN \\ RIO GRANDE DO SUL
}

\author{
Eliana Andréa Severo ${ }^{1}$ \\ Julio Cesar Ferro De Guimarães ${ }^{2}$ \\ Jamile Gai Debarba $^{3}$
}

\begin{abstract}
Resumo: A inovação de processo permite a melhoria do processo produtivo e performance organizacional, no qual o triple bottom line (econômico, ambiental e social), pode ser sustentável, pois reduz os impactos ambientais no meio ambiente e aumenta a competitividade organizacional. As ações sociais desenvolvidas pelas organizações podem beneficiar os colaboradores, assim como a comunidade local. O presente estudo tem como objetivo analisar a inovação de processo, as práticas ambientais e as ações sociais desenvolvidas por duas indústrias metalmecânicas situadas na região norte e nordeste do Rio Grande do Sul (RS). A metodologia utilizada tratou-se de uma pesquisa qualitativa e exploratória, por meio de um estudo de casos múltiplos. Os resultados destacam que as indústrias metalmecânicas desenvolveram importantes inovações de processo as quais abrangem o triple bottom line, no qual reduziram os custos de produção e aumentaram a competitividade organizacional a nível local e mundial, elencando o pilar econômico. No pilar ambiental, foram utilizadas práticas ambientais para segregar e destinar corretamente os resíduos gerados. No pilar social, as ações socias beneficiam diferentes atores, tais como funcionários, crianças, jovens e a comunidade local.
\end{abstract}

Palavras-chave: Inovação de processo. Práticas ambientais. Ações sociais. Indústria metalmecânica.

\begin{abstract}
Process innovation allows the improvement of the production process and organizational performance, in which the triple bottom line (economic, environmental and social), can be sustainable, as it reduces environmental impacts on the environment and increases organizational competitiveness. Social actions developed by organizations can benefit employees, as well as the local community. The present study aims to analyze process innovation, environmental practices and social actions developed by two metal-mechanic industries located in the north and northeast of Rio Grande do Sul (RS). The methodology used was a qualitative and exploratory research through a multiple case study. The results highlight that the metalworking industries have developed important process innovations which include the triple bottom line, in which they have reduced production costs and increased organizational competitiveness at local and global level, listing the economic pillar. In the environmental pillar, environmental practices were used to segregate and correctly dispose of the waste generated. In the social pillar, social actions benefit different actors, such as employees, children, youth and the local community.
\end{abstract}

Keywords: Process innovation. Environmental practices. Social actions. Metal-mechanic industry.

${ }^{1}$ Doutora em Administração, Centro Universitário de Boa Viagem (UniFBV). Recife, Pernambuco, Brasil. elianasevero2@ hotmail.com

(D) 2 Doutor em Administração, Universidade Federal de Pernambuco (UFPE). Recife, Pernambuco, Brasil. juliocfguimaraes@ yahoo.com.br

(D) ${ }^{3}$ Graduada em Administração, Faculdade Meridional (IMED). Passo Fundo. Rio Grande do Sul, Brasil.jamile.jg@ gmail.com

\section{Cite como}

American Psychological Association (APA)

Severo, E. A., Guimarães, J. C. F., \& Debarba, J. G. (2020, jul./dez.). Inovação de processo, práticas ambientais e ações sociais: o caso de duas indústrias metalmecânicas do Rio Grande do Sul. Revista Inovação, Projetos e Tecnologias, São Paulo, 8(2), 119-138. https://doi.org/10.5585/iptec.v8i2.17047. 


\section{Introdução}

A inovação elenca um dos principais pilares da evolução na sociedade, na economia e nas organizações (Severo, Dorion, \& Guimarães, 2020; Wei, Nan, \& Wei, 2020). As empresas devem primar por uma gestão estratégica eficiente e sustentável, abrangendo o triple bottom line, ou seja, o tripé da sustentabilidade, nos pilares econômico, ambiental e social (Goh, Chong, Jack, \& Farias, 2020), atribuindo ênfase na inovação de processos, desta forma as organizações podem entender e descobrir formas de inovar, até mesmo em rotinas diárias departamentais.

O acirramento competitivo entre as empresas está em constante crescimento, desta forma as organizações tendem a oferecer produtos, processos e serviços inovadores com redução do impacto ambiental (Guimarães, Severo, \& Vasconcelos, 2018). Ainda de acordo com os autores, para obter vantagem competitiva, torna-se essencial que as empresas potencializem seu retorno ao mesmo tempo em que avancem em relação à implantação de práticas ambientais e sociais nas operações comerciais.

Neste contexto, as empresas que solidificam o engajamento com a questão da responsabilidade social podem obter uma vantagem competitiva, conquistando a confiança de clientes, fornecedores, investidores e até mesmo da comunidade local na qual está inserida (Morselli \& Ventura, 2017). Os empresários incorporados nestas organizações tornam-se agentes transformadores que exercem influência e possuem aptidão para participar das mudanças ambientais e sociais.

Segundo Daroit e Nascimento (2004), Prajogo (2016) e Sharif, Baark e Lau (2012), a inovação está habitualmente relacionada ao aspecto econômico, sendo tratada apenas como uma forma de obtenção de lucro extra para as organizações, por meio de vantagens competitivas resultante da produção de novos produtos ou processos que incorporem valor para o cliente. Ainda conforme os autores, quando se associa a inovação à questão ambiental, pequenas mudanças em rotinas podem fazer diferença para o alcance de metas e objetivos organizacionais.

Neste contexto, observa-se que junto com a inovação de processos desencadeiam-se impactos ambientais. De acordo com Barbieri, Vasconselos, Andreassi e Vasconcelos, (2010) e Salimova, Guskova e Neretina (2015), o desenvolvimento econômico é algo almejado e perseguido por empresários, o que aponta a aceitação ao movimento da sustentabilidade, nos pilares ambiental e social (Siahaan, Susanti, \& Sudirman, 2020). As organizações são socialmente responsáveis e sustentáveis quando vão além das suas obrigações de respeitar a legislação. Conforme Severo, Guimarães, Dorion e Nodari (2015), as empresas metalmecânicas 
atuam em ambiente competitivo, tornando relevante as questões ambientais e sociais desenvolvidas pelas organizações, pois primam pela performance organizacional.

Perante o exposto, este estudo tem como objetivo analisar as inovações de processos, as práticas ambientais e as ações sociais em duas indústrias metalmecânicas, situada na região norte e nordeste do Rio Grande do Sul (RS).

\section{Referencial teórico}

O referencial teórico aborda as temáticas de inovação de processo, e no triple bottom line, o pilar ambiental que elenca as práticas ambientais, assim como para o pilar social, a responsabilidade social no âmbito organizacional.

\subsection{Inovação de processo}

A inovação de processo pode ser definida como a introdução de uma técnica de produção nova ou melhorada, que envolve procedimentos, maquinários e sistemas que irão assessorar na produção de bens e serviços (Keskin, Wevesr, \& Brezet, 2020; Silva, Sousa, \& Freitas, 2012). Para Dornelas (2003) e Chan, Yee, Dai e Lim (2016), a inovação pode ser baseada na necessidade de processo, desta forma a necessidade leva a invenção e a identificação de novas oportunidades. A inovação de processo trata-se de uma etapa que auxilia no bom funcionamento do processo produtivo.

Conforme Davenport (1994), a inovação salienta um processo no qual apresente modificações importantes, portanto, este método causa modificações na estrutura do processo. Sob esse conceito, o autor destaca que a reengenharia de processo se diferencia da melhoria do processo, no qual tem por objetivo um patamar mais baixo ao que se refere a mudanças.

Segundo a Organização para a Cooperação e Desenvolvimento Econômico (OECD, 2004), a inovação de processo nada mais é que a implantação de um modelo de produção ou fornecimento novo ou substancialmente melhorado, visando a redução de custo na distribuição e produção com uma qualidade melhorada. Davenport (1994) e Sharif et al. (2012) ressaltam que a inovação de processo equilibra as estratégias de: satisfação do cliente, redução do custo e preço dos produtos ou serviços oferecidos pelas organizações, inovação de produtos, aumento da lucratividade, melhoria da receita e aumento no percentual de participação do mercado.

Morris e Brandon (1994) destacam as seguintes fases para abordagem sistemática da implantação de inovação: definir o posicionamento da organização, estabelecer um novo ambiente na empresa, redesenhar o processo, implantar e monitorar o novo processo. Davenport 
(1994) afirma que para a inovação ser implementada existe a necessidade de habilitadores ou facilitadores para que alcancem os objetivos almejados. Comprometimento da alta administração, alinhamento com a estratégia, metodologia para a inovação, gerenciamento da mudança, suporte de tecnologia da informação e equipes de engenharia são identificados como habilitadores da inovação de processo (Jha, Bose, \& Ngai, 2016; Keskin et al., 2020; Morris \& Brandon, 1994).

No que se refere ao processo, para Davenport (1994), é uma sequência de atividades praticadas em um determinado tempo e espaço, com começo, meio e fim, inputs e outputs visivelmente definidos, ou seja, um plano de ação, visando responder e, suprir as solicitações e as expectativas dos clientes da organização.

A inovação de processo, segundo a Pesquisa Industrial de Inovação Tecnológica (PINTEC, 2017), do Instituto Brasileiro de Geografia e Estatística (IBGE), tem como propósito fabricar ou entregar produtos novos ou significativamente melhorados. A inovação de processo pode incluir a inclusão de equipamentos, softwares e técnicas novas ou substancialmente aperfeiçoadas nas tarefas de apoio a fabricação, tais como: planejamento e controle da fabricação, mensuração de desempenho, controle da qualidade, compra, computação (infraestrutura de TI) ou manutenção (IBGE, 2017).

\subsection{Práticas ambientais}

Conforme Goh et al. (2020), no triple bottom line, o pilar ambiental está relacionado as práticas ambientais que diminuem o impacto no meio ambiente. Neste contexto, muitos dos processos industriais geram resíduos, de diferentes tipos e em quantidades variadas. As empresas e a população em geral estão cada vez mais preocupadas com o descarte desses resíduos (Sözer \& Sözen, 2020). Com o passar dos anos, as empresas foram levadas a tomar precauções diante da poluição ambiental que está impedindo o desenvolvimento sustentável das organizações (Simão, 2011; Roque, Severo, Dorion, Roque, \& Guimarães, 2018).

Segundo a ISO 14001 (ABNT, 2004), as normas de gestão ambiental têm por objetivo oferecer as empresas um Sistema de Gestão Ambiental (SGA), que seja eficiente para acompanhar o desempenho econômico e ambiental das organizações, visando os objetivos traçados conforme o planejamento. Conforme Severo (2013), as empresas podem obter redução dos impactos ambientais através de sistemas tradicionais de gestão, algumas das práticas que podem ser adotadas pelas empresas são: Sistema de Gestão de Resíduos (SGR), Estação de 
Tratamento de Efluentes (ETE), Certificado ISSO 14001, Análise do Ciclo de Vida (ACV), Produção mais Limpa (P+L), Reciclagem, Simbiose Industrial (SI), entre outras.

A ABNT (2004) tem como base uma metodologia conhecida como Plan-Do-Check-Act (PDCA), Planejar-Executar-Verificar-Agir, que pode ser descrito da seguinte forma: i) planejar, estabelecer os objetivos e processos necessários para estabelecer concordância com os objetivos da política ambiental da empresa; ii) executar, implementar os processos; iii) verificar, medir e monitorar os processos para relatar os resultados; e, iv) agir, para a continuidade do desempenho do sistema.

Neste cenário, a utilização de práticas ambientais vem sendo utilizada pelas organizações, aumentando seu poder competitivo e diminuindo os impactos ambientais (Severo, 2013; Linder, 2016; Severo, Guimarães \& Dorion, 2018). De acordo com Coral (2002), uma das práticas ambientais mais utilizadas pelas empresas, destinada a atender a certificação ISO 14001, trata-se do SGA e da ETE. Conforme Melville (2010), a adoção de ações ambientais requer novos elementos em relação aos impactos e informações sobre causas e efeitos, além da partilha de conhecimento sobre a efetividade de práticas ambientais.

\subsection{Responsabilidade social}

Segundo Janjua, Sarker e Biswas (2020) e Goh et al. (2020), o pilar social, do triple bottom line, está relacionado as ações sociais das empresas e pessoas que beneficiam a sociedade. Neste cenário, as organizações buscam elaborar trabalhos com ações sociais, além do ramo de negócio estão se preocupando com a sociedade na qual estão inseridas (Mehmood, 2016). Isso tudo faz com que as organizações tenham seu nome ou marca reconhecidos e valorizados (Boulouta \& Pitelis, 2013).

Para Ramos e Gonçalves (2012) e Dellarmelin et al. (2018), quanto mais as organizações valorizam suas marcas fazendo com que os consumidores a relacionem com responsabilidade social, mais impactante serão as consequências relacionada aos negócios. Os programas de responsabilidade social desenvolvidos trazem resultados positivos para organização e para seus colaboradores se desempenhada de forma eficaz e verdadeira (Boulouta \& Pitelis, 2013).

O conceito de responsabilidade social é descrito pelo Instituto Ethos de Empresas e Responsabilidade Social (2015), como o gerenciamento de negócios que elege ética e transparência. De acordo com Carroll (1979), para que a responsabilidade social atenda todas as obrigações de uma organização para com a sociedade, deve introduzir as seguintes categorias: econômica, legal, ética e discricionária. Ainda conforme a autora, essas categorias 
estão relacionadas diretamente com a produção de bens e serviços que a sociedade espera, como respeito às leis, fortalecimento ao trabalho voluntário e respeito aos padrões éticos.

Para Agarwal (2014), a responsabilidade social empresarial oferece recursos para causas de valor social, como doações financeiras ou até mesmo tempo de funcionários para projetos e causas sociais, de acordo com a necessidade ou interesse da sociedade. Neste contexto, a personalidade social dos funcionários pode ser construída quando a empresa é conhecida por uma ampla influência e renome, devido à atuação em programas sociais, passando orgulho aos funcionários em fazer parte dela (Mcshane \& Cunningham, 2012; Skudiene \& Auruskeviciene, 2012).

\section{Método}

Este estudo trata-se de uma pesquisa qualitativa e exploratória por meio de um estudo de casos múltiplos, a fim de identificar os benefícios ocasionados pela inovação de processo, as práticas ambientais e ações sociais em duas indústrias metalmecânicas do RS. Para Gibbs (2009), a pesquisa qualitativa tem por objetivo estruturar modelos e tipologias, teorias para melhor compreensão das questões sociais. Para Creswell (2007), a pesquisa qualitativa é classificada como exploratória devido a possibilidade de embasamento teórico, geralmente suas bases são desconhecidas.

Neste contexto, o escopo do estudo caracteriza-se como estudo de casos múltiplos, se tratando de uma investigação empírica que se dedica a observar e interpretar os dados antes de tirar conclusões, conforme preconiza Yin (2001). Para a elaboração da coleta de dados, primeiramente realizou-se uma pesquisa documental (Gil, 2008), por meio de relatórios de sustentabilidade e responsabilidade social fornecidos pelas empresas (Relatório de Sustentabilidade de 2018), bem como planilhas e documentos das práticas ambientais e ações sociais, os quais são triangulados nos resultados.

Coerentemente, também foi empregada a técnica de entrevista individual semiestruturada em profundidade (Malhotra, Rocha, Laudisio, Altheman, \& Borges, 2005), bem como foi levado em conta o perfil dos profissionais entrevistados. O roteiro da entrevista foi adaptado da pesquisa de Severo (2013), que trata da inovação de processo e da sustentabilidade ambiental em empresas metalmecânicas, e para as ações sociais o relatório de sustentabilidade elaborado pelo Instituto Ethos de Empresas e Responsabilidade Social (2015). O roteiro da entrevista foi validado previamente por dois doutores experts nas áreas de inovação e triple bottom line. 
Neste contexto, foram realizadas oito entrevistas individuais semiestruturadas em profundidade, com os gestores das áreas de: i) inovação; ii) ambiental; e, iii) social. As primeiras cinco entrevistas ocorreram nos meses de abril e maio de 2019, e posteriormente as outras três entrevistas aconteceram em maio de 2020, as quais totalizaram 377 minutos de gravação. Coerentemente, foram quatro entrevistas em cada indústria pesquisada. Vale ressaltar que as entrevistas foram transcritas, totalizando 63 páginas de conteúdo (Gibbs, 2009).

Para a análise das entrevistas semiestruturadas utilizou-se a análise de conteúdo. De acordo com Flick (2009) e Bardin (2006) a análise de conteúdo se refere a uma técnica que utiliza um conjunto das comunicações, ou seja, faz análise das mensagens e conteúdo. De acordo com o exposto, a análise de conteúdo (Bardin, 2006) elencou as categorias de análise $a$ priori, embasadas nos objetivos da pesquisa:
i) inovação de processo;
ii) práticas ambientais; e,
iii) ações sociais.

\section{Análise e discussões dos resultados}

\subsection{Estudo de casos múltiplos}

Por questões estratégicas o nome das indústrias analisadas não será divulgado, sendo denominada de empresa Afla e Beta. A indústria Alfa faz parte de um conglomerado de nove companhias, com sede na região nordeste do RS, atuando principalmente no setor de soluções para o transporte. O conglomerado de empresas conta com ações listadas na B3 e cerca de 13 mil acionistas, conforme o Relatório de Sustentabilidade de 2018. A indústria Alfa desenvolve soluções para o transporte de pessoas, na geração do lucro com sustentabilidade, na confiança, na inovação e na tecnologia. Atualmente a organização está com 70 anos de história, e tem uma presença global e liderança nos setores de transportes fora-de-estrada e autopeças (Relatório de Sustentabilidade de 2018). Neste contexto, a Alfa pode ser considerada uma referência global em transporte, pois possuí 20 unidades industriais, e está presente em 100 países, de todos os continentes.

O grupo Beta tem uma das suas sedes localizada no norte do RS. Criada em 1828 sob a forma de uma modesta forjaria, especializou-se na fabricação de balanças e de aparelhos de pesagem. A principal mudança acontece em 1864 quando, tirando o maior partido possível da linha férrea Paris Estrasburgo e do excepcional período de prosperidade que a França passava na época, instala-se em Saverne para iniciar a fabricação de máquinas agrícolas. No início do 
século XX, várias dezenas de máquinas são produzidas todas as semanas nas oficinas de Saverne, oficinas estas que possuem igualmente sua própria forja. Tornada alemã em 1871, e novamente francesa em 1918, o grupo Beta é nessa época uma empresa regional que trabalha essencialmente para agricultura da região francesa da Alsacia. Após uma década de crescimento, a Segunda Guerra mundial vem brutalmente interromper o desenvolvimento da empresa.

Em 2002, entra uma nova etapa, onde iniciou-se o plano de expansão mundial, anunciando a aquisição de uma empresa americana, que é a líder em misturadoresdistribuidores de adubo. A aquisição desta empresa apresenta de fato uma etapa fundamental no desenvolvimento e crescimento da empresa Beta, pois pela primeira vez passou a produzir máquinas fora do solo francês. No ano de 2005, o grupo Beta adquire sociedade brasileira com uma empresa especialista na fabricação de semeadoras e plantadoras de plantio direto de precisão para culturas como soja, algodão e milho. A partir de 2010 o grupo Beta passa a ser proprietário e não mais acionista da unidade do norte do RS. Neste contexto, a Tabela 1 apresenta a caracterização das indústrias e dos entrevistados. Coerentemente, a Alfa apresenta 70 anos de história e a Beta 11 anos de presença no Brasil. No que tange a industrialização de seus produtos, a Alfa produz reboques e semirreboques, vagões, veículos fora-de-estrada, autopeças e serviços financeiros. Já a indústria Beta produz semeadoras, plantadoras, adubadoras, pulverizadores, trituradores para acostamento, cortadores especializados de capins, segadoras, espalhadores de forragens, ancinhos, enfardadoras, empacotadoras, misturadores de ração, desensiladoras, distribuidores de ração e distribuidores de esterco. 
Tabela 1 - Caracterização das indústrias e entrevistados

\begin{tabular}{|c|c|c|}
\hline Nome da Indústria & Alfa & Beta \\
\hline $\begin{array}{l}\text { Tempo de atuação no } \\
\text { mercado }\end{array}$ & 70 anos & $\begin{array}{l}\text { No Brasil: } 11 \text { anos; } \\
\text { Grupo Beta: } 188 \text { anos }\end{array}$ \\
\hline Principais produtos & $\begin{array}{l}\text { Reboques e semirreboques, vagões, } \\
\text { veículos fora-de-estrada, autopeças e } \\
\text { serviços financeiros. }\end{array}$ & $\begin{array}{l}\text { Semeadoras; } \\
\text { Plantadoras; } \\
\text { Adubadoras; } \\
\text { Pulverizadores; } \\
\text { Trituradores para Acostamento; } \\
\text { Cortadores Especializados de } \\
\text { Capins; } \\
\text { Segadoras; } \\
\text { Espalhadores de Forragens; } \\
\text { Ancinhos; Enfardadoras; } \\
\text { Empacotadoras; } \\
\text { Misturadores de Ração; } \\
\text { Desensiladoras; } \\
\text { Distribuidores de Ração; } \\
\text { Distribuidores de Esterco. }\end{array}$ \\
\hline Faturamento anual & $\begin{array}{l}\text { Conglomerado: em } 2018 \text { receita bruta de } \\
\text { R } \$ 6 \text { bilhões. A divisão de autopeças foi } \\
\text { responsável por } 50,8 \% \text { da receita líquida } \\
\text { consolidada (R } \$ 2,2 \text { bilhões), enquanto a } \\
\text { divisão montadora (que inclui reboques, } \\
\text { semirreboques, veículos especiais e } \\
\text { vagões) respondeu por } 45,3 \% \text { (R } \$ 1,9 \\
\text { bilhão). Serviços financeiros compuseram } \\
\text { os demais } 3,8 \% \text {. }\end{array}$ & $\begin{array}{l}\text { Unidade no norte do RS: em } 2018 \\
\text { R } \$ 18 \text { milhões }\end{array}$ \\
\hline $\begin{array}{l}\text { Quantidade de } \\
\text { funcionários }\end{array}$ & $\begin{array}{l}\text { Conglomerado: } 11.000 \text { colaboradores } \\
\text { Alfa: } 4.800 \text { colaboradores }\end{array}$ & $\begin{array}{l}\text { Grupo Beta: } 5.200 \text { colaboradores } \\
\text { Beta: } 460 \text { colaboradores }\end{array}$ \\
\hline Entrevistados & $\begin{array}{l}\text { E1 (Engenheiro de Produção) } \\
\text { E2 (Engenheiro Ambiental) } \\
\text { E6 (Gerente Industrial) } \\
\text { E7 (Coordenador do Setor Socioambiental) }\end{array}$ & $\begin{array}{l}\text { E3 (Engenheiro Mecânico e } \\
\text { Gerente da Qualidade) } \\
\text { E4 (Bacharel em Química e } \\
\text { Coordenadora do setor ambiental) } \\
\text { E5 (Psicóloga responsável pelo } \\
\text { Recrutamento e Seleção e } \\
\text { desenvolvedora dos Projetos } \\
\text { Sociais) } \\
\text { E8 (Coordenador de Manufatura) }\end{array}$ \\
\hline $\begin{array}{l}\text { Tempo de atuação na } \\
\text { empresa }\end{array}$ & $\begin{array}{l}\text { E1 }-16 \text { anos } \\
\text { E2 }-15 \text { anos } \\
\text { E6 }-13 \text { anos } \\
\text { E7 }-5 \text { anos }\end{array}$ & $\begin{array}{l}\text { E3 - } 10 \text { anos } \\
\text { E4 }-8 \text { anos } \\
\text { E5 }-4 \text { anos } \\
\text { E8 }-2 \text { anos }\end{array}$ \\
\hline $\begin{array}{l}\text { Tempo de duração da } \\
\text { entrevista }\end{array}$ & $\begin{array}{l}\text { E1 - } 97 \text { Minutos; E2 - } 29 \text { minutos; E6 - } \\
23 \text { minutos; E7 - } 21 \text { minutos. }\end{array}$ & $\begin{array}{l}\text { E1 - } 90 \text { Minutos; E2 - } 57 \\
\text { Minutos; E3 - } 34 \text { Minutos; E8 - } \\
26 \text { minutos. }\end{array}$ \\
\hline
\end{tabular}

Fonte: Elaborado pelos autores (2020).

\subsection{Inovação de processo}

A pesquisa realizada nas indústrias abrangeu as informações referente ao período de 2014 a 2018. Vale ressaltar que a inovação de processo está atrelada ao conceito da OECD (2004), caracterizando-se como uma nova ou melhoria do processo de produção. Identificou-se diversas inovações de processo realizadas nas organizações, as quais foram descritas na Tabela 2. 
Neste contexto, é possível observar vários avanços no que se refere as inovações de processo nas indústrias, o que ocasionou uma melhoria no processo produtivo, redução de custos de produção e de lead time. Na indústria Alfa, implementou-se o corte a laser e corte plasma, a pintura $e$-coat e metodologia de produção mais limpa $(\mathrm{P}+\mathrm{L})$, adquiriu-se também a nova máquina de pneus e os gabaritos de soldagens de vigas. Já na indústria Beta foi implementado o centro de usinagem, a fundição de peças complexas, a reforma de máquinas, a pré montagem e a expedição, assim como a montagem de reservatórios de adubo e máquinas de demonstração.

Tabela 2 - Inovação de processo desenvolvidas pelas indústrias

\begin{tabular}{|l|l|}
\hline Alfa & \multicolumn{1}{|c|}{$\begin{array}{l}\text { Inovação de processo } \\
\text { Corte a laser; Corte plasma; Máquina de pneus; Gabarito de soldagens de vigas; } \\
\text { Pintura e-coat; Metodologia de produção mais limpa (P+L). }\end{array}$} \\
\hline Beta & $\begin{array}{l}\text { Centro de usinagem; Fundição de peças complexas; Reforma de máquinas; Pré } \\
\text { montagem; Expedição; Montagem de reservatórios de adubo; Máquinas de } \\
\text { demonstração. }\end{array}$ \\
\hline
\end{tabular}

Fonte: Elaborado pelos autores (2020).

Conforme Silva et al. (2012), a inovação de processo visa a aquisição de maquinários que contribuam para o desenvolvimento produtivo de um setor ou linha de produção. Foi possível observar que as organizações investiram na aquisição de maquinários para que o processo produtivo fosse aprimorado auxiliando na eficácia do processo.

Nesta perspectiva, de acordo E1, a Alfa atingiu alto know-how da tecnologia existente para os processos produtivos, trabalhando para os processos existentes, pois conta com uma equipe de engenharia, treinada para o desenvolvimento de inovações de processo. Ainda conforme o E1, a indústria desenvolveu um processo em parceria com fornecedores, atrelados a uma linha para montar pneu com roda (máquina de pneus e o processo de montagem), que tem capacidade para a montagem de 2.500 pneus por dia, onde a máquina monta o pneu na roda, enche e calibra o pneu.

A indústria Beta trabalha com um comitê de alteração de projetos, que avalia as modificações ou inovações sugeridas pelos colaboradores. Para compor o comitê foram selecionados funcionários da engenharia, qualidade, compras, direção, métodos e processo e produção. As inovações de modificação de peças são documentadas em projetos, já as inovações de processo são apresentadas para os diretores nas reuniões gerenciais, no qual se demostra os custos e os benefícios ocasionados pelas modificações. 
(...) os funcionários têm livre acesso aos gestores para sugerirem modificações. O gestor leva para o comitê que avalia a ideia (E3).

Contudo, uma das modificações realizadas no processo da Beta foi aplicada no setor de usinagem, com aquisição de um torno com alimentador de barra, pois anteriormente o processo de fabricação de uma peça era distribuído em cinco estações de trabalho, demandando profissionais qualificados em cada estação, ferramentas adequadas e um alto tempo de produção, o que fazia com que os custos fossem maiores. Com essa aquisição, demanda somente um profissional e baixo ferramental. Houve redução de $70 \%$ dos custos com despesas de pessoal, e o processo de produção se tornou mais ágil, o que de acordo com o IBGE (2017), a inovação de processo pode incluir a inclusão de equipamentos, softwares e técnicas novas ou substancialmente aperfeiçoadas nas tarefas de apoio a fabricação. Neste contexto, a inovação de processo no setor de usinagem teve um investimento em novos equipamentos, do qual foi mensurado um retorno de investimento em 20 meses.

(...) toda inovação está aliada à tecnologia ou máquinas novas, toda a inovação só consegue ver se ganhou ou perdeu se existe algum indicador (E3).

Uma inovação de processo da Beta relevante, ocorreu na reforma de máquinas internamente, na qual até 2015 era de responsabilidade do pós-vendas, porém o índice de insatisfação do cliente era alto, pois o processo de reforma era demorado, a qualidade era insatisfatória, os custos eram altos e muitas vezes as peças eram trocadas sem uma avaliação. Neste cenário, existia um sério problema de organização, conforme foi destacado pelo entrevistado E3. Corroborando, Davenport (1994) e Tidd, Bessant e Pavitt (1997) destacam que a inovação salienta um processo no qual apresente modificações importantes, portanto, este método causa modificações na estrutura do processo de produção.

Outro processo que ficou modificado na Beta, trata-se das máquinas de demonstração, ou seja, essas máquinas já plantaram, são usadas, e apresentam um grande desgaste. Até 2015 o produto era vendido nessas condições, o cliente vinha até a empresa e fazia o preço, partindo de um determinado valor que a máquina valia. Neste contexto, o índice de insatisfação era percebido, pois não era o que ele queria muitas vezes receber. Quando a máquina chegava na propriedade não funcionava, e muitas vezes faltavam componentes.

(...) era um desgaste enorme tanto para a empresa que perdia dinheiro quanto para o produtor que adquiriu o equipamento, toda a máquina de demonstração era um problema, os custos com envio de peças e deslocamento de técnicos era muito alto (E3).

$\mathrm{Na}$ Beta, ainda sobre a inovação de processo, o setor de pré-montagem passou por uma restruturação. O layout da produção foi alterado com a organização das mesas de trabalho, assim como a disponibilização dos componentes mais próximos aos montadores, evitando 
deslocamentos desnecessários, e diminuindo tempo de montagem da caixa, sistematicamente para agilizar o processo. Com as alterações, ocorreu uma redução de $20 \%$ do lead time do processo produtivo para a montagem da caixa.

(...) a inovação de processo melhorou a nosso processo produtivo, com a redução de lead time, e otimização da mão de obra, ocasionando redução de custos para a empresa, podendo ser mais competitiva (E8).

As inovações de processo desenvolvidas pelas indústrias Alfa e Beta, são alterações, modificações de processo já existentes, ou até mesmo a aquisição de novo know-how para o sistema de produção, que para Dornelas (2003) e Chan et al. (2016) está fundamentada na necessidade de processo, levando a invenção e a identificação de novas oportunidades.

\subsection{Práticas ambientais}

No que diz respeito ao pilar ambiental, a indústria Alfa utiliza o Sistema de Gerenciamento de Resíduos (SGR) nas inovações de processo, a fim de segregar corretamente as classes de resíduos perigosos e não perigosos, de acordo com a sua periculosidade e toxicidade. A organização também utiliza o Sistema de Gestão Ambiental (SGA) que é certificado pela Norma ISO 14001 (ABNT, 2004), além de indicadores ambientais, tais como a geração de resíduos, consumo de água e energia. Quanto as práticas ambientais, ao tratamento e disposição final dos resíduos gerados, são utilizadas: segregação de resíduos, estação de tratamento de efluentes (ETE), reciclagem, co-processamento, reprocessamento externo, compostagem e aterro sanitário (Relatório de Sustentabilidade, 2018).

A indústria Beta possui um SGR, com a finalidade de segregar corretamente os resíduos perigosos (Classe I) e os não perigosos (Classe II). Essas práticas ambientais estão diretamente relacionadas com o plano de gestão que se encontra no processo ASE (Segurança e Meio Ambiente), que é da certificação ISO 9001. Essa matriz tem todas as ações a serem realizadas durante o ano. Um dos valores da empresa está relacionado com o meio ambiente e os materiais levam em consideração a preservação do meio ambiente desde a fase de concepção. A empresa preocupa-se com o impacto ambiental, tratando adequadamente os resíduos gerados (Relatório de Sustentabilidade, 2018).

Ressalta-se que as indústrias Alfa e Beta possuem controle de consumo de energia, água e de gases poluentes, emitidos pelos setores de pintura, usinagem, fundição e solda. Neste cenário, existe uma equipe responsável pelo controle ambiental, a qual é responsável por controlar o desempenho ambiental e os indicadores ambientais preconizados pela Fundação Estadual de Proteção Ambiental (FEPAM) do RS. Estes resultados corroboram como os 
pressupostos de Salimova et al. (2015), no qual as organizações estão aderindo ao movimento da sustentabilidade, ou seja, o lucro é extremamente relevante, mas as questões ambientais são também primordiais.

A empresa Beta possui parcerias para realizar a reciclagem correta dos materiais, os papeis e plásticos são vendidos para uma empresa de reciclagem. Os valores recebidos acabam voltando para os funcionários como uma bonificação ou brinde pelo descarte correto dos mesmos, o que conforme Simão (2011) são precauções devido ao crescimento da poluição. As sucatas metálicas são vendidas para a Gerdau, a empresa vende as sucatas para a fabricação de aço, isso faz com que a empresa contribua para menor utilização dos recursos naturais ao reduzir o consumo energético e o uso de insumos como calcário e carvão para produção do aço. Diminuindo então a emissão dos gases que contribuem para o efeito estufa.

No que tange aos benefícios, a aquisição de uma máquina no setor de usinagem fez com que $70 \%$ dos óleos que eram descartados como contaminados pela produção fossem reutilizados na indústria Beta. Isso refletiu nos custos da empresa, passando do descarte desses óleos para o reaproveitamento. Também se observou a redução nos custos com energia elétrica e água. Perante o exposto, a Tabela 3 apresenta as práticas ambientais utilizadas pelas indústrias. Consoante isso, a Alfa utiliza como práticas ambientais, o SGR, o SGA, a certificação isso 14001, o consumo de água e de energia, a ETE, a reciclagem, o co-processamento, o reprocessamento externo, a compostagem e o aterro sanitário. Já a indústria Beta, tem como práticas ambientais, o SGR, a reciclagem, o controle do consumo de água e de emissões atmosféricas, a descontaminação, o aterro sanitário, a ETE, e a reciclagem de areia de fundição.

Tabela 3 - Práticas ambientais utilizadas pelas indústrias

\begin{tabular}{|c|c|}
\hline \multicolumn{2}{|c|}{ Práticas ambientais } \\
\hline Alfa & $\begin{array}{l}\text { SGR; SGA; Certificação ISO 14001; Consumo de água; Consumo de energia; } \\
\text { ETE; Reciclagem; Co-processamento; Reprocessamento externo; Compostagem; } \\
\text { Aterro sanitário. }\end{array}$ \\
\hline Beta & $\begin{array}{l}\text { SGR; Reciclagem; Controle do consumo de água; Controle de emissões } \\
\text { atmosféricas; Descontaminação; Aterro sanitário; ETE; Reciclagem de areia de } \\
\text { fundição. }\end{array}$ \\
\hline
\end{tabular}

Fonte: Elaborado pelos autores (2020).

\subsection{Ações de responsabilidade social}

As ações de responsabilidade social fazem parte da missão e valores das indústrias Alfa e Beta, pois as organizações assumiram compromissos com os Stakeholders de serem empresas cidadãs. A segurança e o bem-estar dos colaboradores, o respeito ao meio ambiente, a qualidade 
das relações com os terceiros, são preocupações permanentes para assegurar o desenvolvimento de maneira duradoura e equilibrada, o que para Machado (2014), é primordial para as organizações. Coerentemente, Boulouta e Pitelis (2013) destacam que os programas de responsabilidade social ocasionam resultados positivos para organização e para seus colaboradores, bem como para a comunidade em geral.

Dentre as ações sociais, a Alfa tem como princípios promover ações em educação, cultura, assistência social, educação para o trânsito e estimular a prática do voluntariado. Esse é o objetivo do Instituto da indústria Alfa, organização que coordena todos os programas sociais do conglomerado de empresas. Com a missão de preparar crianças e adolescentes para o exercício da cidadania, para uma melhor qualidade de vida e um futuro promissor (Relatório de Sustentabilidade 2018). As ações de responsabilidade social estimulam a busca do bem-estar, por meio do incentivo a educação, a saúde, lazer, esporte e cultura. A Alfa coordena projetos e programas de cunho preventivo na área da saúde, nos casos de dependência química, de prevenção ao uso de drogas, da praticidade de esportes, ginásticas, jogos de interação e educação para o trânsito.

A indústria Beta apresenta como indicadores sociais: alimentação; saúde; segurança e medicina do trabalho; auxílio educação; capacitação; transporte; qualidade de vida; participação nos lucros ou resultados; associação para os funcionários e encargos sociais. Para o público externo a empresa apresenta os seguintes indicadores: esporte e doações a entidades carentes.

Uma das maiores ações desenvolvidas pela Beta foi a implantação do programa Jovem Capaz. Trata-se de um programa de inclusão social com parceria da Associação dos Pais e Amigos dos Excepcionais (APAE) e o Serviço Nacional de Aprendizagem Industrial (SENAI). O programa prepara os jovens para chegarem no mercado de trabalho, bem como trabalha a questão comportamental e individual.

(...) são realizadas reuniões com os pais, a assistente social da APAE faz o acompanhamento do desenvolvimento de cada um, vem até a empresa trimestralmente para realizar conversas com os jovens, discutir dificuldades e propor melhorias (E5).

A Beta possui programas na área da saúde e de cunho preventivo, pode ser citada a campanha da vacinação, distribuição de preventivos, práticas esportivas. Ainda a cada trimestre, em parceria com o Serviço Social da Industria (SESI), é alojado no pátio da empresa um consultório móvel para atendimento dos colaboradores. Conforme Agarwal (2014), a empresa oferece recursos em virtude de valor social, que é um dos modelos apresentados em suas teorias. 
Tanto a Alfa, quanto a Beta, investem em treinamento e desenvolvimento de seus funcionários, visando o crescimento profissional e evolução pessoal de cada colaborador, bem como cursos para capacitação para líderes. De cunho ambiental, ressalta-se o desenvolvimento de projetos ambientais para conscientização dos funcionários, quanto ao consumo de energia, água e separação dos resíduos. Com o objetivo de alertar os funcionários quanto a importância e preservação do meio ambiente.

A indústria Alfa e Beta realizam doações a diversas entidades carentes na região nordeste e norte do RS, buscando aproximar a comunidade da empresa, devido à atuação em programas sociais (Skudiene \& Auruskeviciene, 2012), ocasionando empatia aos funcionários em fazer parte dela (Mcshane \& Cunningham, 2012), assim como impacto positivo e responsável das indústrias na comunidade local, o que reflete na imagem e marca organizacional. A Tabela 4 destaca as ações sociais desenvolvidas pelas indústrias.

Tabela 4 - Ações sociais desenvolvidas pelas indústrias

\begin{tabular}{|l|l|}
\hline Alfa & $\begin{array}{c}\text { Ações sociais } \\
\text { Desenvolvimento de líderes; Treinamentos; Cursos de formação e } \\
\text { aprimoramento; Incentivos à graduação, pós-graduação, cursos }\end{array}$ \\
& $\begin{array}{l}\text { técnicos e de idiomas; Sucessão de gestores. Meio ambiente; Bem } \\
\text { estar; Segurança no trânsito; Formação Básica e } \\
\text { Profissionalizante; Doações a Entidades Carentes. }\end{array}$ \\
\hline Beta & $\begin{array}{l}\text { Treinamentos; Cursos de formação e aprimoramento; Incentivos } \\
\text { educacionais; Bem-estar; Qualidade de vida; Beta sorriso; Escola } \\
\text { de líderes; Doações a entidades carentes; Incentivos ao Esporte. }\end{array}$ \\
\hline
\end{tabular}

Fonte: Elaborado pelos autores (2020).

\section{Considerações finais}

Na presente pesquisa foi possível analisar a inovação de processo, as práticas ambientais e as ações sociais desenvolvidas por duas indústrias metalmecânicas situadas na região norte e nordeste do (RS). As inovações de processo desenvolvidos pelas indústrias, as modificações de maquinários e equipamentos e a incorporação de know-how para produção, estão de acordo com os pressupostos de Silva et al. (2012), pois contribuem para o desenvolvimento produtivo, de um setor ou linha de produção.

As práticas ambientais são efetivamente utilizadas nas indústrias, bem como em virtude do SGA a Alfa possui a certificação ISO 14001, o que atesta as suas práticas ambientais. Já a Beta, adere as suas práticas ambientais ao padrão exigido pelo órgão que regulamenta a operação (ISO 9001), visto que os setores da indústria estão engajados no que que se refere aos 
cuidados com a segregação e destino dos resíduos, assim como a proteção do meio ambiente. Estes achados corroboram com os estudos de Simão (2011) e Severo et al. (2015), nos quais as empresas foram levadas a tomar precauções, mediante a busca da sustentabilidade ambiental e a preservação dos recursos naturais, diante da poluição ambiental a qual está agredindo o meio ambiente e a qualidade de vida das pessoas.

Destaca-se que a adoção das ações sociais está ocasionando um impacto positivo para as indústrias, por meio das diversas ações que as mesmas disponibilizaram para a comunidade local, tais como educação, cultura, assistência social e doações a diversas entidades carentes, o que contribui para a imagem e consolidação da marca das indústrias, pois são diversas ações sociais para o público interno e a sociedade. Conforme Ramos e Gonçalves (2012) e Dellarmelin, Moraes, Hoeckesfeld, Severo e Hahn (2018), as organizações que conseguirem valorizar suas marcas, fazendo com que os consumidores a relacionem com responsabilidade social, poderão ter uma melhoria na performance organizacional.

Evidencia-se que as indústrias investem em inovação de processo, práticas ambientais e ações sociais para fortalecer os negócios, reduzir o impacto sobre o meio ambiente e compartilhar os avanços com a sociedade. Os benefícios ocasionados pela implementação das ações sociais visam a qualidade de vida dos funcionários, assim como o crescimento e desempenho das indústrias perante ao mercado mundial.

As contribuições gerenciais referem-se aos benefícios oriundos das inovações de processo, práticas ambientais e ações sociais desenvolvidas pelas indústrias, as quais trazem um diferencial competitivo que contribuem para a qualificação da tomada de decisão a nível gerencial. Referente às contribuições acadêmicas, entende-se, que por abordar os temas de inovação de processo, práticas ambientais e ações sociais, que são temáticas primordiais para as organizações contemporâneas, possa servir como fonte de interesse de novos estudos acadêmicos, que queiram aprofundar-se no referido assunto.

No decorrer da pesquisa observou-se algumas limitações, ressaltando que o presente estudo trata de um estudo de casos em duas organizações, limitando-se assim a generalização dos resultados. Por conseguinte, sugere-se para estudos futuros pesquisas empíricas aplicadas a um número maior de organizações, comparando-se setores, regiões e a interpretação de diferentes atores, inseridos neste contexto. 


\section{Referências}

ABNT. Associação Brasileira de Normas Técnicas. (2004). Nbr ISO 14001. Sistemas de gestão ambiental: requisitos com orientação para uso. Associação Brasileira de Normas Técnicas, Rio de Janeiro.

Agarwal, A. (2014). The new spectrum of corporate social responsibility in emerging economies. International Journal of Engineering and Management Research. 4(1), 3236.

Barbieri, J. C., Vasconcelos, I. F. G., Andreassi, T., \& Vasconcelos, F. V. (2010). Inovação e sustentabilidade: modelos e proposições. Revista de Administração de Empresas. 50(2), 146-154. https://doi.org/10.1590/S0034-75902010000200002.

Bardin, L. (2006). Análise de conteúdo, 70 ed., Lisboa.

Boulouta, I., \& Pitelis, C. N. (2014). Who needs CSR? The impact of corporate social responsibility on national competitiveness. Journal of Business Ethics. 119, 349-364. https://doi.org/10.1007/s10551-013-1633-2.

Carroll, A. B. (1979). Three-dimensional conceptual model of corporate performance. Academy of Management Review. 4(4), 497-505. https://doi.org/10.5465/amr.1979.4498296.

Chan, H. K., Yee, R. W., Dai, J., \& Lim, M. K. (2016). The moderating effect of environmental dynamism on green product innovation and performance. International Journal of Production Economics. 181, 384-391. https://doi.org/10.1016/j.ijpe.2015.12.006.

Coral, E. (2002). Modelo de planejamento estratégico para a sustentabilidade empresarial. (Tese de Doutorado em Engenharia de Produção) - Universidade Federal de Santa Catarina. Florianópolis, SC, Brasil.

Creswell, J. W. (2007). Projeto de pesquisa: métodos qualitativos, quantitativos e misto. 2 ed., Artmed, Porto Alegre.

Daroit, D., Nascimento, L. F. (2004). Dimensões da inovação sob o paradigma do desenvolvimento sustentável. Encontro da Associação Nacional de Pós-graduação e Pesquisa em Administração - ENANPAD, 28, Curitiba, Anpad.

Davenport, T. H. (1994). Reengenharia de processos, Campus, Rio de Janeiro.

Dellarmelin, M. L., Moraes, J. P., Hoeckesfeld, L., Severo, E. A., \& Hahn, I. S. (2018). The influence of green branding on purchase intention, willingness to pay and consumers' emotional response: an experimental study. Latin American Journal of Management for Sustainable Development. 4(1), 69-82. https://doi.org/10.1504/LAJMSD.2018.091327.

Dornelas, J. C. A. (2003). Empreendedorismo corporativo: como ser empreendedor, inovar e se diferenciar na sua empresa, Campus, Rio de Janeiro. 
Flick, U. (2009). Introdução à pesquisa qualitativa, 3 ed., Artmed, São Paulo.

Gibbs, G. (2009). Análise de dados qualitativos, Bookman, Porto Alegre.

Gil, A. C. (2008). Métodos e técnicas de pesquisa social, 6. ed., Atlas, São Paulo.

Goh, C. S., Chong, H. Y., Jack, L., \& Faris, A. F. M. (2019). Revisiting triple bottom line within the context of sustainable construction: a systematic review. Journal of Cleaner Production. 252, 119884. https://doi.org/10.1016/j.jclepro.2019.119884

Guimarães, J. C. F. de, Severo, E. A., \& Vasconcelos, C. R. M. de. (2018). The influence of entrepreneurial, market, knowledge management orientations on cleaner production and the sustainable competitive advantage. Journal of Cleaner Production, 174, 16531663. https://doi.org/10.1016/j.jclepro.2017.11.074.

IBGE - Instituto Brasileiro de Geografia e Estatística. (2017). Pesquisa PINTEC 2017. Instituto Brasileiro de Geografia e Estatística, Rio de Janeiro.

Instituto Ethos de Empresas e Responsabilidade Social. (2015). Valores, transparência e governança. Recuperado em 12 de, setembro, 2015 de https://www3.ethos.org.br/conteudo/gestao-socialmente-responsavel/valorestransparencia-e-governanca/\#

Janjua, S. Y., Sarker, P. K., \& Biswas, W. K. (2020). Development of triple bottom line indicators for life cycle sustainability assessment of residential bulidings. Journal of Environmental Management. 264, 110476. https://doi.org/10.1016/j.jenvman.2020.110476.

Jha, A. K., Bose, I., \& Ngai, E. W. T. (2016). Platform based innovation: the case of Bosch India. International Journal of Production Economics. 171, 250-265. https://doi.org/10.1016/j.ijpe.2015.09.037.

Keskin, D., Wevesr, R., \& Brezet, H. (2020). Product innovation processes in sustainability-oriented ventures: A study of effectuation and causation. Journal of Cleaner Production. 263, 121210. https://doi.org/10.1016/j.jclepro.2020.121210.

Linder, M. (2016). Determinants of economic performance of environmental technologybased offers: a cross-sectional study of small Swedish firms. International Journal of Innovation and Sustainable Development. 10(3), 237-259. https://doi.org/10.1504/IJISD.2016.077502.

Machado, C. M. (2014). Tecnologia da informação aplicada à gestão da responsabilidade social. Congresso Nacional de Excelência em Gestão - Cneg, 5, Rio de Janeiro e Niterói. Rio de Janeiro e Niterói, CNEG. CD-ROM.

Malhotra, N. K., Rocha, I., Laudisio, M. C., Altheman, E., \& Borges, F. M. (2005). Introdução à pesquisa de marketing, 1 ed., Prentice Hall, São Paulo. 
Mcshane, L., \& Cunningham, P. (2012). To thine own self be true? Employees' judgments of the authenticity of their organization's corporate social responsibility program. Journal of Business Ethics. 108, 81-100. https://doi.org/10.1007/s10551-011-1064-X.

Mehmood, A. (2016). Institutional forms of social innovation. International Journal of Innovation and Sustainable Development. 10(3), 300-311. https://doi.org/10.1504/IJISD.2016.077512.

Melville, N. P. (2010). Information systems innovation for environmental sustainability. MIS Quarterly. 34(1), 1-21.

Morris, D., \& Brandon, J. (1994). Reengenharia: reestruturando sua empresa, Makron Books, São Paulo.

Morselli, A., \& Ventura, M. (2017). Measuring corporate social responsibility disclosure and the financial crisis in Italy. comparison of the two years prior to the crisis (2006) and the two years since the onset of the crisis (2010). Journal of Applied Economic Sciences. 12(4), 1025-1037.

OECD. Organização para a Cooperação e Desenvolvimento Econômico. (2004). Manual de Oslo: diretrizes para coleta e interpretação de dados sobre inovação, 3 ed., Tradução FINEP, Brasília.

PINTEC. Pesquisa de Inovação Tecnológica. (2017). Recuperado em 07 de Abril, 2020, de https://www.ibge.gov.br/estatisticas/multidominio/9141-pesquisa-deinovacao.html?=\&t=destaques

Prajogo, D. I. (2016). The strategic fit between innovation strategies and business environment in delivering business performance. International Journal of Production Economics. 171, 241-249.

Ramos, M. A, \& Gonçalves, T.C.C. (2012). Interesses estratégicos da responsabilidade socioambiental empresarial em uma montadora automobilística: a dinâmica entre a prática da responsabilidade socioambiental e os negócios da organização. Congresso nacional de Excelência em Gestão, 8 e 9 jun.

Roque, P. G., Severo, E. A., Dorion, E, C. H., Roque, E. S., \& Guimarães, J. C. F. de. (2018). The dilemma of environmental sustainability in a developing country: environmental crimes in southern Brazil. Business Strategy \& Development. 1(1), 43 52. https://doi.org/10.1002/bsd2.10.

Salimova, T., Guskova, N., \& Neretina, E. (2015). Education for sustainable development in Russia: problems and challenges. International Journal of Innovation and Sustainable Development. 9(3-4), 246-261. https://doi.org/10.1504/IJISD.2015.071855.

Severo, E. A. (2013). Inovação e sustentabilidade ambiental nas empresas do arranjo produtivo local metalomecânico automotivo da serra gaúcha. (Tese de Doutorado em Administração). Universidade de Caxias do Sul. Caxias do Sul, RS, Brasil. 
Severo, E. A., Dorion, E. C. H., \& Guimaraes, J. C. F. (2020). Hélices holísticas de inovação e ecoinovação: drivers para o desenvolvimento sustentável. Gestão e Desenvolvimento. 17, 57-81. https://doi.org/10.25112/rgd.v17i2.2151.

Severo, E. A., Guimarães, J. C. F. de., Dorion, E. C. H., \& Nodari, C. H. (2015). Cleaner production, environmental sustainability and organizational performance: an empirical study in the Brazilian Metal-Mechanic industry. Journal of Cleaner Production. 96, 118-125. https://doi.org/10.1016/j.jclepro.2014.06.027.

Severo, E. A., Guimarães, J. C. F. de, \& Dorion, E. C. H. (2018). Cleaner production, social responsibility and eco-innovation: generations' perception for a sustainable future. Journal of Cleaner Production. 186, 91-103. https://doi.org/10.1016/j.jclepro.2018.03.129.

Sharif, N., Baark, E., \& Lau, A. K. W. (2012). Innovation activities, sources of innovation and R\&D cooperation: evidence from firms in Hong Kong and Guangdong Province, China. International Journal of Technology Management. 59(3-4), 203-234. https://doi.org/10.1504/IJTM.2012.047244.

Siahaan, Y., Susanti, E., \& Sudirman, A. (2020). Effect of firm characteristics on firm value through triple bottom line disclosure: Pharmaceutical companies listed on Indonesia stock exchange. International Journal of Scientific and Technology. 9(2), 2228-2234.

Simão, J. (2011). Gerenciamento dos resíduos sólidos industriais em uma empresa de usinagem sobre o enfoque da produção mais limpa. (Dissertação de Mestrado em Hidráulica e Saneamento). Escola de Engenharia de São Carlos da Universidade de São Paulo. São Carlos, SP, Brasil.

Silva, M. E, Sousa, I G, \& Freitas, L S. (2012). Processo de inovação: um estudo no setor moveleiro de Campina Grande - PB. Revista de Administração e Inovação. 9(1), 257 279. https://doi.org/10.5773/rai.v1i1.584

Sözer, H., \& Sözen, H. (2020). Waste capacity and its environmental impact of a residential district during its life cycle. Energy Reports. 6, 286-296. https://doi.org/10.1016/j.egyr.2020.01.008.

Skudiene, V., \& Auruskeviciene, V. (2012). The contribution of corporate social responsibility to internal employee motivation. Baltic Journal of Management. 7(1), 4967. https://doi.org/10.1108/17465261211197421.

Tidd, J., Bessant, J., \& Pavitt, K. (1997). Managing innovation: integrating technological, Market and Organisational Change, 3 ed., John Wiley and Sons Ltd.

Yin, R. K. (2001). Estudo de caso: planejamento e métodos. 2. ed., Bookman, Porto Alegre.

Wei, Y., Nan, H., \& Wei, G. (2020). The impact of employee welfare on innovation performance: Evidence from China's manufacturing corporations. International Journal of Production Economics. 228, 107753. https://doi.org/10.1016/j.ijpe.2020.107753. 